\title{
Consumption Concept and People's Choice of Financial Assets: A Research Based on CHFS 2011
}

\author{
Pan Zhu \\ School of Economics, Jinan University, Guangzhou, China \\ Email: zhupan0902@163.com
}

Received 16 March 2016; accepted 21 April 2016; published 26 April 2016

Copyright (C) 2016 by author and Scientific Research Publishing Inc.

This work is licensed under the Creative Commons Attribution International License (CC BY).

http://creativecommons.org/licenses/by/4.0/

(c) (i) Open Access

\begin{abstract}
As an important part of culture, consumption concept can not only influence people's attitude about worth and wealth, but also their economical behavior and financial decisions. Based on CHFS2011 database, this paper analyzes the relationship between consumption concept and people's choice of financial assets. The empirical results of this paper show that those who hold forward and positive consumption concept are more willing to hold risk assets than those who hold traditional and conservative consumption concept.
\end{abstract}

Keywords

Consumption Concept, Financial Assets, CHFS

\section{Introduction}

Family finance has increasingly become a focus of research, also family financial market participants and choice of household financial assets became the core problem of domestic financial research. According to Chinese financial household survey database, the financial market participation rate is only $11.5 \%$, participation in the stock market is $8.8 \%$. The performance between urban households and rural households is relatively different. In a word, in China, family financial market participation rate is still low. What factors influence Chinese domestic financial market to participate in decision-making and asset allocation? In this paper, we will investigate the relationship between consumption concept and the choice of financial assets based on large- scale micro data of Chinese family financial.

\section{Literature Review}

\section{Relevant Literatures of Residents' Financial Assets Selection}

Branson has systematically discussed the financial assets selections, holding that the assets selection of the eco- 
nomic agent is mainly based on the expected rate of return, the level of the risk and liquidity strength. Subsequently, the researchers found that resident's assets selection is not only influenced by the microeconomic factors as wages, house property and demographics. Heaton and Lucas found a high correlation between salary and stock holdings, high-income groups hold greater proportion of stock holdings [1]. Campbell found that the factors such as age, gender, education, health status can affect the financial asset allocation of the residents in accordance with econometric analysis [2]. Mankiw and Zeldes noted that, in addition to income, gender, age, education level, the marital status and background risk would also impose an impact on the allocation of the residents' financial assets [3].

With in-depth research, more and more scholars tried to investigate the behavior of financial assets selections of residents from the perspective of behavioral finance. Vissing-Jorgensen believed that overconfidence of the residents may lead to centralized holding of the risk assets by analyzing the impact of cognitive biases on the investment decisions of the residents [4]. Bertaut and Starr concluded the impact of consumer expectations, credibility, social interaction, investor sentiment and other factors on residents' involvement in the stock market [5]. Li Tao studied the 2004 survey data on the residents of Guangdong Province and found that social interaction and credibility would promote resident participation in the stock market, but also the social interaction can obviously impose positive effects on those undereducated participants in the stock market [6]. Dezhu Ye and Liyan Zhou conducted empirical analysis on the data from Chinese family financial investigations, and found that there is a significant negative correlation between the sense of happiness and the risk assets of the residents. The more happy the people are, the more willing the people would rather maintain their current living conditions, the more risk-averse, the higher degree of concern for the future, and the less corresponding short-term behavior is [7].

\section{Description of Data and Variables}

\subsection{Introduction of Samples and Data}

The data applied in the empirical research of this paper is from the China Institute household financial survey by the Southwest University of Finance and Economics in 2011. The survey covered 25 provinces, 80 counties, and 310 communities, totally 8438 samples, which are designed to track household survey for a comprehensive system of family financial sector. The database includes housing and financial assets, liabilities and credit card, income, consumption, social security and insurance, demographic characteristics and other household micro-level information. The data is highly targeted with detailed household financial assets of the information, which is valuable to explore the concept of consumer choice of their financial assets from the micro-level. Excluding some outliers and missing data, received a total of 5660 valid samples. The data sample has a very complete representation of data quality is relatively high.

\subsection{Variables}

\subsubsection{Explained Variables}

The explanatory variables selected in the paper are: the stock holdings, holdings of risky assets. According to the answers of the interviewed for the question "Are you currently engaged in the following investment activities (stocks, funds, bonds, financial products, futures, warrants, gold, foreign investment)", if one is to invest stocks, the stock holdings value will be of 1 , otherwise 0 ; if one is in possession of one or more such risky assets, the level of risk assets held value is for 1 , and otherwise 0 .

\subsubsection{Explanatory Variables}

The explanatory variable selected in this paper is consumption concept. This paper choose the credit card held by residents to measure their consumption concept, if hold a credit card, the residents and their families prefer a forward and positive concept of consumption, if not, the residents and their families prefer a traditional and conservative concept of consumption. According to the answer of the surveyed to the question that: "Do you have a credit card", no matter how many cards they hold, as long as they have a credit card, the variable of consumption concept values can be assigned to 1 , otherwise zero.

\subsubsection{Control Variable}

1) Household income. This paper selects income includes wages and income from transfers, other income and 
so on. which is obtained by summing the total income of the family. Choosing the natural logarithm replaced household income, so as to ensure normal distribution.

2) Insurance participation. According to the answers of the respondents to the question that "Are you currently participate in the following social security programs (health insurance, social insurance, etc)", if anyone is involved in at least one of them, the insurance participation will be assigned to 1 , otherwise 0 .

3) Housing ownership. Real estate, as a large asset may have crowding effect on the investments in stocks and risky assets. According to the answer of the respondents to the question that "Do you have your own house", if they have their own houses, the variable of the house holdings will be assigned to 1 , otherwise 0 .

4) Education background. Chinese household financial questionnaire, according to China's existing education, the education background is divided into 9 levels from the uneducated to the graduate student. What's more, the value of the level of the educated is corresponding to be assigned to an integer ranging within 1 - 9 .

5) Risk attitude: According to the respondents to the question that "If you have an asset that you are willing to choose which investment projects", which assigned to 5.4.3.2.1 replaced risk attitude.

6) Demographic variables. Marital status, the married is assigned to 1 , otherwise 0 ; gender, male is assignedto1, female is assigned to 0 ; political status, communists are assigned to 1 , others are assigned to 0 (Table 1 ).

\section{Model Setup}

As the explained variable in this paper is a binary dummy variable, the regression analysis is conducted on the relationship between religion and residents asset selection by means of Probit model of determination on the nature. Probit model is set as follows:

$$
Y_{i}=1\left(\alpha_{i} \text { credit }+\beta_{i} X+\mu_{i}\right)
$$

$\mu_{i} \sim N\left(0, \sigma^{2}\right), Y_{1}=1$ at $i=1$ represents the resident holdings, $Y_{1}=0$ indicates that the resident does not hold any stocks, $Y_{2}=1$ at $i=2$ indicates that the resident holds the risky assets, $Y_{2}=0$ indicates that the resident does not hold risky assets. Credit serves as the consumption concept variable, $X$ represents the control variable used in this paper.

\section{Empirical Analysis}

\subsection{Descriptive Statistics of Variable}

As we can be seen from Table 2, the people who hold stocks and risky assets respectively account for $6.3 \%$ and $9.5 \%$, indicating that the residents in China is inactive to participate in the capital market, and people's financial

Table 1. Model specific description of each variable.

\begin{tabular}{|c|c|c|}
\hline Variable Name & Variable Description & Variable Declaration \\
\hline Stock & Whether they hold shares & $1=$ hold, $0=$ do not hold \\
\hline Risk assets & Whether they hold risky assets & $1=$ hold risky assets, $0=$ do not \\
\hline Credit & Whether they hold credit card & $1=$ hold, $0=$ do not hold \\
\hline Household income & Ln (household income) & $\begin{array}{l}\text { Ln (total income of career earnings } \\
\text { and other income) }\end{array}$ \\
\hline Risk & Risk attitude & Assignment 1 - 5, smaller value indicates more appetite for risk \\
\hline Insurance & Insurance participation & $1=$ participate in, $0=$ do not \\
\hline House & Whether to have a house & $1=$ have, $0=$ do not \\
\hline Gender & Gender & $1=$ male, $0=$ female \\
\hline Education & Education background & $\begin{array}{c}1 \text { - } 9 \text { respectively corresponding to education background from low to high } \\
\text { degree }\end{array}$ \\
\hline Political & Political status & $1=$ Communist, 0 = other \\
\hline Marital & Marital status & $1=$ married, $0=$ other \\
\hline Health & Health status & Assignment 1 - 5, with the larger value for healthier condition \\
\hline Price & Expected price & Assignment 1 - 5, larger value for higher price \\
\hline House price & Expected house price & Assignment 1 - 5, larger value for higher house price \\
\hline
\end{tabular}


Table 2. Descriptive statistics of variable.

\begin{tabular}{|c|c|c|c|c|c|}
\hline Variables & Observations & Mean & Std & Min & $\operatorname{Max}$ \\
\hline Stock & 5660 & 0.06324 & 0.24342 & 0 & 1 \\
\hline Risk assets & 5660 & 0.09539 & 0.29378 & 0 & 1 \\
\hline Gender & 5660 & 0.58805 & 0.49223 & 0 & 1 \\
\hline Education & 5660 & 3.26338 & 1.55547 & 1 & 9 \\
\hline Household income & 5660 & 10.1514 & 1.21191 & 0 & 14.91 \\
\hline Credit & 5660 & 0.06006 & 0.23762 & 0 & 1 \\
\hline House & 5660 & 0.92811 & 0.25834 & 0 & 1 \\
\hline Risk & 5660 & 3.90002 & 1.21267 & 1 & 5 \\
\hline Consumption & 5660 & 2.68098 & 1.03061 & 1 & 5 \\
\hline Insurance & 5660 & 0.90037 & 0.31562 & 0 & 1 \\
\hline Price & 5660 & 1.91168 & 0.8228 & 1 & 5 \\
\hline House price & 5660 & 2.11888 & 0.91174 & 1 & 5 \\
\hline Political & 5660 & 0.15775 & 0.36454 & 0 & 1 \\
\hline Marital & 5660 & 0.88324 & 0.32117 & 0 & 1 \\
\hline Health & 5660 & 2.63823 & 0.94934 & 1 & 5 \\
\hline
\end{tabular}

awareness has yet to be improved. About 6 percent of respondents said they have had some credit cards. According to the rising living standards, residents discarded the traditional conservative concept of consumption, more and more people start using credit cards to excessive consumption so as to enhance their quality of life. In addition, the average risk appetite was 3.9, indicating that most people are risk averse, which also explains the lower participation in the stock market and capital market from the other side.

\subsection{Basic Regression Results}

Considering the huge regional differences have different impact on consumer attitudes, the paper will be divided the full sample into urban and rural residents so as to illustrate the relationship between residents and the household financial assets. Regression results of the model are shown in Table 3.

From the empirical results, the residents hold active credit card, their consumption is more forward and positive, then they have depth understanding of relevant financial matters than others. They are more willing to hold significant assets; on the contrary, the residents do not have active credit card, the concept of consumption is relatively conservative and traditional, for the reason that they have not depth understanding of relate financial tools, also will not hold stocks and risks of financial assets, which intuitionally is understandable. Due to the regional differences, compared to rural residents, urban residents have more significant relationship with the concept of consumer choice of household financial assets, and urban attitudes toward risk in household financial assets choice are very significant, but rural residents' risk attitudes are not significant.

\section{Conclusions}

Consumption concept as a significant component of culture will influence people's value, view of wealth, economic behavior and also financial decision making. The discussion about consume and financial assets in China is still lacking. On basis of CHFS2011 database, this paper attempts to explore this topic, and aims to understand the financial assets selection behavior of Chinese residents more completely.

On basis of CHFS2011 database, this paper attempts to discuss the relationship between consumption concept and residents' financial assets selection by building Probit regression model. By controlling related variables as 
Table 3. Basic regression results of the model.

\begin{tabular}{|c|c|c|c|c|c|c|}
\hline \multirow[t]{2}{*}{ Variables } & \multicolumn{2}{|c|}{ Urban Resident } & \multicolumn{2}{|c|}{ Rural Resident } & \multicolumn{2}{|c|}{ Full Sample } \\
\hline & Stock & Risky assets & Stock & Risky assets & Stock & Risky assets \\
\hline \multirow[t]{2}{*}{ Credit } & $0.301^{* *}$ & $0.354^{* * *}$ & $0.437^{*}$ & \multicolumn{2}{|c|}{$0.415^{*} 0.340^{* * *}$} & $0.363^{* * *}$ \\
\hline & (2.89) & (3.63) & (2.06) & $(2.32)$ & (3.73) & (4.31) \\
\hline \multirow[t]{2}{*}{ Risk } & $-0.174^{* * *}$ & $-0.149^{* * *}$ & -0.0631 & -0.0556 & $-0.104^{* * *}$ & $-0.082^{* * * *}$ \\
\hline & $(-5.88)$ & $(-5.46)$ & $(-1.19)$ & $(-1.36)$ & $(-4.34)$ & $(-3.82)$ \\
\hline \multirow[t]{2}{*}{ House price } & $0.190^{* * *}$ & $0.161^{* * *}$ & -0.0286 & 0.0658 & $0.154^{* * *}$ & $0.141^{* * * *}$ \\
\hline & (5.25) & $(4.85)$ & $(-0.40)$ & $(1.27)$ & (5.11) & (5.27) \\
\hline \multirow[t]{2}{*}{ Household income } & $0.281^{* * *}$ & $0.291^{* * *}$ & $0.240^{* * *}$ & $0.229^{* * *}$ & $0.300^{* * *}$ & $0.310^{* * *}$ \\
\hline & $(6.57)$ & $(7.43)$ & (3.59) & $(4.54)$ & $(9.01)$ & (10.59) \\
\hline \multirow[t]{2}{*}{ Education } & $0.0780^{* * *}$ & $0.111^{* * * *}$ & $0.202^{* * *}$ & $0.220^{* * * *}$ & $0.190^{* * *}$ & $0.220^{* * *}$ \\
\hline & (3.41) & (5.33) & (3.40) & $(4.67)$ & (10.18) & (13.19) \\
\hline \multirow[t]{2}{*}{ House } & 0.250 & 0.223 & -0.0731 & -0.0246 & 0.136 & 0.112 \\
\hline & (1.87) & (1.90) & $(-0.30)$ & $(-0.12)$ & (1.19) & (1.13) \\
\hline \multirow[t]{2}{*}{ Insurance } & $0.466^{* *}$ & $0.505^{* * *}$ & 0.166 & 0.123 & $0.214^{*}$ & $0.209^{*}$ \\
\hline & (3.27) & (3.94) & $(0.87)$ & $(0.80)$ & $(2.22)$ & $(2.46)$ \\
\hline \multirow[t]{2}{*}{ Gender } & $-0.184^{* *}$ & $-0.130^{*}$ & -0.0624 & -0.0849 & $-0.232^{* * *}$ & $-0.186^{* * *}$ \\
\hline & $(-2.59)$ & $(-2.02)$ & $(-0.44)$ & $(-0.80)$ & $(-3.89)$ & $(-3.53)$ \\
\hline \multirow[t]{2}{*}{ Health } & 0.0598 & $0.0814^{*}$ & $-0.208^{* *}$ & $-0.109^{*}$ & 0.0174 & 0.0366 \\
\hline & $(1.44)$ & $(2.16)$ & $(-2.81)$ & $(-2.01)$ & $(0.52)$ & $(1.25)$ \\
\hline \multirow[t]{2}{*}{ _Cons } & $-5.051^{* * *}$ & $-5.176^{* * *}$ & $-4.624^{* * *}$ & $-4.668^{* * *}$ & $-5.657^{* * *}$ & $-5.721^{* * *}$ \\
\hline & $(-9.91)$ & $(-11.19)$ & $(-5.38)$ & $(-7.00)$ & $(-14.10)$ & $(-16.30)$ \\
\hline$N$ & 2387 & 2387 & 3273 & 3273 & 5660 & 5660 \\
\hline
\end{tabular}

t statistics in parentheses, ${ }^{*} p<0.05,{ }^{* * *} p<0.01,{ }^{* * *} p<0.001$.

much as possible and fully considering the model's endogenous influence, we discovered that consumption concept and residents' stock purchase and risky assets holding were remarkably and positively related. That is to say, people with forward and positive consumption concept are more inclined to hold stock and risky assets.

\section{References}

[1] Heaton, J. and Lucas, D. (2000) Portfolio Choice in the Presence of Background Risk. The Economic Journal, 110, 1-26. http://dx.doi.org/10.1111/1468-0297.00488

[2] Campbell, J.Y. (2006) Household Finance. The Journal of Finance, 61, 1553-1604. http://dx.doi.org/10.1111/j.1540-6261.2006.00883.x

[3] Mankiw, N.G. and Zeldes, S.P. (1991) The Consumption of Stockholders and Non-Stockholders. Journal of Financial Economics, 29, 97-112. http://dx.doi.org/10.1016/0304-405X(91)90015-C

[4] Vissing-Jorgensen, A. (2008) Limited Stock Market Participation and the Equity Premium Puzzle. NBER Working Paper.

[5] Bertaut, C.C. and Starr, M. (2006) Household Portfolios in the United States. FEDS Working Paper, No. 2000-26.

[6] Li, T. (2006) Social Interaction, Trust, and Stock Market Participation. Journal of Economy, 1, 34-45.

[7] Ye, D.Z. and Zhou, L.Y. (2002) The Sense of Happiness and Household Assets Selection. New Economy, 22, 52-55. 